\title{
AUDIÊNCIA DE CUSTODIA E SEUS REFLEXOS NO SISTEMA PENAL BRASILEIRO
}

\author{
Vitória Celeste Dias Oliveira Gomes
}

Universidade do Oeste Paulista - UNOESTE, Curso de Direito, Presidente Prudente, SP. E-mail: vitoriadias_28@hotmail.com

\section{RESUMO}

A audiência de custódia caracteriza-se pelo objetivo primordial de garantir contato pessoal da pessoa presa com o juiz após sua prisão em flagrante. A implantação surgiu da reprodução existente em tratados internacionais, como o Pacto de San José da Costa Rica, objetivando os direitos humanos dos presos. Conduzindo-se tal audiência pelos princípios Da Verdade Real, Garantia da Ampla Defesa, Presunção de Inocência, Dignidade da Pessoa Humana. Assim, esse trabalho utiliza-se do método dedutivo legal, baseando-se na interpretação de doutrinas, legislação e livros sobre o tema abordado, composta de uma análise de modo geral. Diante de vários reflexos, conclui-se que o tema apresentado influi com grande ajuda na redução da superlotação no sistema carcerário, em gastos com a custódia dos presos, bem como na ajuda ao sistema prisional, no estímulo de outras medidas alternativas cabíveis ao recolhimento dos presos, dentre outras destacadas posteriormente.

Palavras-chave: Audiência de Custódia, Medidas Alternativas, Direitos Humanos.

\section{AUDIENCE OF CUSTODY AND ITS REFLECTIONS IN THE BRAZILIAN CRIMINAL SYSTEM}

\begin{abstract}
The custody hearing is characterized by the primary objective of ensuring personal contact of the person arrested with the judge after his arrest in flagrante. The implantation appeared with reproduction existing in international treaties, such as the Pact of San José of Costa Rica, aiming at the human rights of prisoners. Conducted such an audience, by the principles of the Real Truth, Guarantee of the Ample Defense, Presumption of Innocence, Dignity of the Human Person. How to use the legal deductive method, based on the interpretation of rules, according to the literature and the topic addressed, as a general analysis.

In the face of a number of reflections, it is concluded that this topic has a great influence on reducing overcrowding in the prison system, on spending on custody of prisoners, as well as on helping the prison system, stimulating alternative means available to the prisoners' others later highlighted.

Keywords: Hearing of Custody, Alternative Measures, Human Rights.
\end{abstract}




\section{INTRODUÇÃO}

A audiência de custódia, denominada popularmente como audiência de apresentação, é sintetizada pela Convenção Americana de Direito Humanos (pacto de San José da Costa Rica) e demais Pactos Internacionais, sendo certo que deixa claro sobre os Direito Humanos, instruindo que o preso deve ser transportado, sem demora, à presença do juiz para que o mesmo analise a infração cometida, verificando a necessidade e adequação, responsável por efetuar outras mediadas alternativas, e ainda avaliar eventuais casos de tortura ou maus-tratos com o preso encaminhado.

É extremamente importante salientar que o Pacto de San José da Costa Rica é norma supralegal, e que podemos declarar inválida qualquer lei que vá contra o Pacto, através do controle de convencionalidade das normas. Dessa forma, seu cumprimento é compulsório e não discricionário.

Toda essa situação é baseada na proteção dos direitos humanos, em âmbito nacional caracterizada pela Constituição federal, e internacional, caracterizada pelo Pacto de San José da Costa Rica e o sistema Interamericano de Direito Humanos, garantindo o efetivo controle judicial das prisões.

No Brasil, o projeto piloto de implantação desta audiência foi lançado em fevereiro de 2015 pelo Conselho Nacional de Justiça (CNJ) em conjunto com o Ministério da Justiça e o Tribunal de Justiça do Estado de São Paulo - TJSP. Sendo adotada em todos os tribunais do país, regulamentada pela Resolução de no 213, de 15 de dezembro de 2015, baixada pelo Conselho Nacional de Justiça (CNJ).

Muitos são os princípios que regem essa problemática, podendo destacar o Principio da Dignidade da Pessoa Humana, sendo de estrita importância na criação do instituto da audiência de custódia e demais normas provenientes do Pacto de São José da Costa Rica, norteado por ele, as condições mínimas de existência, saúde física e moral, em aplicação da aludida audiência, como por exemplo o preso ser apresentado em vinte e quatro horas ao juízo competente, inibindo-se a pratica de atos que ferem tal princípio mencionado, como: torturas, maus-tratos e agressões.

A audiência de custódia tem como principal objetivo o respeito aos direitos fundamentais da pessoa submetida à prisão. Ela garante a presença física do preso em flagrante perante o juiz, viabiliza esse contato mister, o qual permite que o preso sinta-se mais próximo do processo, tendo como direito, a pessoa presa, de mencionar o contraditório pleno e efetivo antes da tomada das medidas como a conversão da prisão em flagrante em prisão preventiva. Com essa problemática, evitam-se prisões desnecessárias, atenuando-se a superlotação carcerária e os gastos que decorrem da manutenção de presos provisórios. Permite ainda conhecer e tomar providências necessárias e adequadas. Garante-se um controle judicial célere e eficaz sobre a legalidade, necessidade e adequação da prisão cautelar.

Logo, este trabalho objetiva estudar e analisar, de forma geral, o instituto de audiência de custodia como garantia das normas que devem ser aplicadas na apresentação do preso perante o Juízo Competente e a importância desse aludido contato. Podendo assim refletir o assunto, em possíveis medidas alternativas, possibilitando chances em ter a prisão revista, auxiliando no "desafogamento" do Poder Judiciário e combate de prisões ilegais, feitas de maneira arbitrária ou desnecessária, e ainda analisar a integridade física do preso.

\section{METODOLOGIA}

Para realização do trabalho abordado foi empregado o método dedutivo e o procedimento será o analítico, servindo-se de pesquisa bibliográfica e documental, para a elaboração do estudo serão utilizados materiais relativos à audiência de custódia, sendo eles: livros a respeito e artigos científicos publicados em revistas jurídicas, baseando-se na interpretação de doutrinas, legislação sobre o tema abordado, e análise de modo geral. 


\section{DA AUDIÊNCIA DE CUSTÓDIA}

Diversos são os resultados da audiência de custódia, podendo-se destacar no que tange ao Conselho Nacional de Justiça - CNJ: O relaxamento de eventual prisão ilegal (art. 310, I, do Código de Processo Penal); a concessão de liberdade provisória, com ou sem fiança (art. 310, III, do Código de Processo Penal); a substituição da prisão em flagrante por medidas cautelares diversas (arts. 310, II, parte final, e 319 do Código de Processo Penal); a conversão da prisão em flagrante em prisão preventiva (art. 310, II, parte inicial, do Código de Processo Penal); e a análise do cabimento da mediação penal, o que evita a judicialização do conflito e corrobora para a instituição de práticas restaurativas; além de encaminhamentos de natureza assistencial e o encaminhamento de providências para a apuração de eventual prática de maus-tratos ou de tortura durante a prisão.

Além de propiciar um vasto rol positivo para o sistema carcerário de todos os países, as audiências de custódia criaram diversas mudanças de paradigma no sistema da justiça criminal. Fazendo com que a ideia de uma pessoa encarcerada seja uma das providências para a diminuição de crimes, sendo certo que essa maneira de enxergar o sistema penitenciário está atrelada aos interpretes da justiça criminal. Ela afeta o pensamento de muitos da sociedade, que não conseguem compreender que o encarceramento não soluciona o problema da criminalidade. Quanto mais presos, mais presídios e mais prisões, levando a conclusão de que esses fatos não trazem a segurança que desejada.

Portanto, ela auxilia a consideração sobre a inevitabilidade de manutenção das prisões efetuadas, podendo "abrir os olhos" dos magistrados frente a tantas medidas alternativas existentes, sendo capaz de substituí-las, a fim de não serem aplicadas somente penas privativas de liberdade, fornecendo ao magistrado um suporte para a melhor análise e subsunção do fato delituoso cometido à norma. 


\section{FLUXOGRAMA}

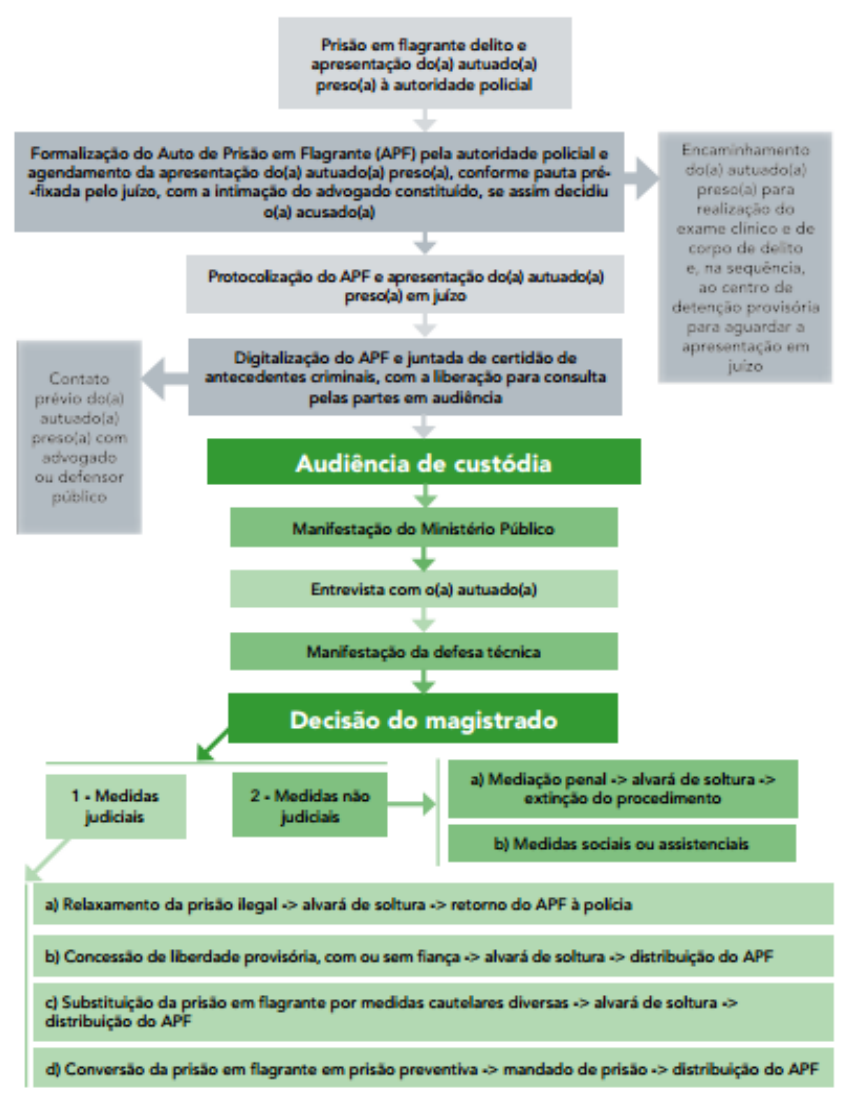

\section{REFLEXOS DA AUDIÊNCIA DE CUSTÓDIO NO ORDENAMENTO JURÍDICO BRASILEIRO}

Para o Conselho Nacional de Justiça, a audiência de custódia é a audiência de apresentação do autuado, preso em flagrante delito, perante um juiz, no prazo de vinte e quatro horas, permitindo-lhe o contato pessoal, de modo a assegurar o respeito aos direitos fundamentais da pessoa submetida ao cárcere, devendo o magistrado analisar a prisão sob o aspecto da legalidade, da necessidade e da adequação da sua continuidade ou da eventual concessão de liberdade, com ou sem a imposição de outras medidas cautelares (CNJ - Concelho Nacional de Justiça, 2015).

Doutrinariamente não há divergência quanto a sua definição. É a audiência que consiste na condução do preso, sem demora, à presença de uma autoridade judicial que deverá, a partir do prévio contraditório estabelecido entre o Ministério Público e a defesa, exercer um controle imediato da legalidade e da necessidade da prisão, assim como apreciar questões relativas à pessoa do cidadão conduzido, notadamente a presença de maus tratos ou tortura (PAIVA, 2017).

É o ato realizado, após a prisão em flagrante do agente, no prazo máximo de 24 horas, para que o juiz, pessoalmente, avalie a sua legalidade e promova as medidas cabíveis: manter a prisão, relaxar o flagrante ou conceder liberdade provisória (NUCCI, 2016).

Da análise do projeto inicial implantado no Estado de São Paulo, da Resolução no 213/2015 do CNJ e da doutrina especializada no tema, importante destacar que a audiência de custódia apresenta grandes finalidade. Uma a ser destacada seria a adequação ao processo penal interno aos tratados internacionais de direitos humanos. Apesar de confirmados há mais de duas décadas, os tratados internacionais de direitos humanos não vinham sendo cumpridos tampouco respeitadas as garantias convencionais neles expostas, notadamente, o direito da pessoa presa de ser conduzida, sem demora, perante um juiz. É justamente para viabilizar esse direito humano do preso manter contato imediato com o juiz que surge a audiência de custódia.

Nessa linha de raciocínio adverte Raphael Melo (2016, p. 1633):

Também pode ser apontada como finalidade da audiência de custódia a compatibilização do 
nosso processo penal com os tratados internacionais incorporados ao nosso ordenamento jurídico há mais de vinte anos. Ou seja, por meio da audiência de custódia materializamos a garantia de apresentação do preso ao juiz competente, embora com significado atraso.

Caio Paiva, Defensor Público Federal (2017, p. 45), é bastante enfático ao declarar que:

[...] a principal e mais elementar finalidade da implementação da audiência de custódia no Brasil é ajustar o processo penal brasileiro aos tratados internacionais de direitos humanos. Tal premissa implica considerar que as finalidades da audiência de custódia, ainda que não convençam os seus opositores, não os desobriga de observar o seu cumprimento. Pouca ou nenhuma importância teria o DIDH se cada país dispusesse de uma margem de apreciação a respeito da utilidade dos direitos e garantia veiculadas nos tratados a que - voluntariamente aderiram

Assim, já decidiu a Corte Interamericana de Direitos Humanos que "O controle judicial imediato é uma medida tendente a evitar a arbitrariedade ou ilegalidade das detenções, tomando em conta que num Estado de Direito corresponde ao julgador garantir os direitos do detido, autorizar a adoção de medidas cautelares ou de coerção, quando seja estritamente necessário, $e$ procurar, em geral, que se trate o investigado de maneira coerente com a presunção de inocência". Da mesma forma, após ressaltar a especial vulnerabilidade do preso, a Corte IDH já ressaltou que "o juiz é garante dos direitos de toda pessoa que esteja na custódia do Estado, pelo que Ihe corresponde a tarefa de prevenir ou fazer cessar as detenções ilegais ou arbitrárias e garantir um tratamento conforme o princípio da presunção de inocência".

As audiências de custódia completaram um ano de funcionamento em fevereiro de 2016, e, mesmo nesse curto espaço de tempo, já foi possível medir avanços significativos e projetar resultados otimistas no tratamento da questão penal e carcerária para as próximas décadas. Essa foi a conclusão do monitoramento das audiências de custódia na capital paulista, com a presença do presidente do Conselho Nacional de Justiça (CNJ) e do Supremo Tribunal Federal (STF) (Ministro Ricardo Lewandowski, 2016)

O estudo "As audiências de custódia na cidade de São Paulo: avanços e desafios" foi organizado pelo Instituto de Defesa do Direito de Defesa (IDDD), representante da sociedade civil associado ao CNJ na implementação do projeto. Pesquisadores do IDDD monitoraram quase 700 audiências de custódia no Fórum Criminal da Barra Funda no ano de 2015, traçando um perfil dos presos em flagrante - negros, pobres, de baixa instrução, réus que praticam crimes de roubo, furto ou tráfico de drogas - e avaliando o funcionamento da metodologia na prática. Encontraram, por exemplo, a baixa presença de advogados nas delegacias durante a prisão em flagrante (5\%) e o alto percentual de presos que não sabem do que estão sendo acusados (84\%).

Para o presidente do IDDD, o fato de $39 \%$ dos casos analisados serem convertidos em liberdade provisória não indica que o Judiciário está soltando pessoas perigosas aleatoriamente, mas, sim, evitando prisões desnecessárias. Para ele, o ponto mais positivo das audiências de custódia é modificar a cultura de que só o encarceramento resolve (Augusto Botelho,2017).

\section{CONCLUSÃO}

Através do tema abordado, possibilitou-se explanar sobre os direitos e princípios que regem a audiência de custódia, podendo salientar sempre o principio da Dignidade da Pessoa Humana, onde prevalece o mínimo de preceitos, extremamente fundamentais, tais como, direito a saúde, integridade física e moral etc.

Constatou-se ainda que, de forma majoritária, a defendida audiência tem um grande impacto em toda a sociedade brasileira, priorizando o contato do preso com o magistrado (juiz), o que gera uma aproximação do delituoso com o seu próprio processo, ficando claro que nesse momento, o mesmo terá uma abertura para informar ao juiz o fato ocorrido, de modo a efetuar 
sua ampla defesa, e contraditório. Portanto, a pessoa detida se prevalecerá de tais princípios mencionados, permanecendo com sua integridade física e moral em perfeitas condições.

De um modo geral, fica esclarecido que de tais audiências de custódia, surgem medias alternativas passíveis de aplicação pelo juiz, adotando a substituição das penas privativas de liberdade, em penas, por exemplo: restritivas de direito, medidas compulsórias, controlamento eletrônico, dentre outras. Acrescenta-se assim quão necessária se mostra a referida audiência para o "desafogamento" do poder judiciário, o que pode ser exposto por meio dos números que se referem à diminuição das prisões efetuadas, simplificando de forma clara o entendimento do tema abordado.

\section{REFERÊNCIAS}

Audiência de Custodia. Disponível em:

http://www.cnj.jus.br/sistema-carcerario-e-execucao-penal/audiencia-de-custodia. Acesso em 16 agos. 2018;

Concelho Nacional De Justiça - Audiência De Custodia. Disponivel em: http://www.cnj.jus.br/files/conteudo/arquivo/2016/09/0a99a0ab0eb26b96fdeaf529f0dec09b.pdf . Acesso 04 jul. 2018;

Concelho Nacional De Justiça - Corte Interamericana de Direitos Humanos. Disponível em: http://www.cnj.jus.br/poder-judiciario/relacoes-internacionais/corte-interamericana-de-direitoshumanos-corte-idh. Acesso em 05 jul.2018;

FONSECA ANDRADE, Mauro; RODRIGO ALFLEN, Pablo. Audiência de Custódia - Da boa intenção à Boa Técnica. Fundação Escolar Superior do Ministério Público;

PAIVA, Caio. Audiência De Custódia E O Processo Penal Brasileiro. $2^{\circ}$ Edição. Empório do Direito. 2017;

NUCCl, Guilherme. Manual do Direito Penal e Execução Penal. $13^{\circ}$ Edição. Editora Forense. 2016;

MELO, Raphael. Audiência De Custódia no Processo Penal. Editora D’Placido.2016. 